\title{
PROPERTIES IMPROVEMENT ON POLYESTER FABRIC USING POLYVINYL ALCOHOL
}

\author{
J. Jeyakodi Moses ${ }^{1} \bowtie(D)$, P. Sathish ${ }^{2} \square$ (D) M. Keerthivasan ${ }^{3}$, R.J. Pragadeesh ${ }^{3}$ and A. Pranesh ${ }^{3}$ \\ ${ }^{1}$ Associate Professor, Department of Applied Science, PSG College of Technology, Coimbatore 641004, India \\ ${ }^{2}$ Assistant Professor, Chemistry, Hindusthan College of Engineering and Technology, Coimbatore 641032, \\ India \\ ${ }^{3}$ B.Sc. Applied Science Students, Department of Applied Science, PSG College of Technology, Coimbatore \\ 641004, India
}

Received 20 July 2021

Accepted 07 August 2021

Published 21 August 2021

\section{CorrespondingAuthor}

J. Jeyakodi Moses, jjmoses2k2@gmail.com DOI 10.29121/ijetmr.v8.i8.2021.1013

Funding: This research received no specific grant from any funding agency in the public, commercial, or not-for-profit sectors.

Copyright: (C) 2021 The Author(s). This is an open access article distributed under the terms of the Creative Commons Attribution License, which permits unrestricted use, distribution, and reproduction in any medium, provided the original author and source are credited.

OPEN ACCESS

\section{ABSTRACT}

Polyethylene terephthalate is one of the important synthetic ester polymeric material used in widespread areas. In textile industry, this fibrous material finds use in most of the garment and apparel applications due to its ease of handling, maintenance, and drying and competes with cotton materials. However, due to the maximum hydrophobic behavior, this textile material gives number of issues like accumulation of statics, negligible moisture content, poor comfort and aesthetic characters. Hence, in order to use this polyester material in the general textile industries particularly for garment and apparel productions, it is necessary to increase to some extent of its hydrophilic character by the application of some suitable chemicals like polyvinyl alcohol. In these context, in this work an attempt is made to treat the polyethylene terephthalate fabric with sodium hydroxide followed by polyvinyl alcohol so as to increase the aesthetic properties. The output received after the polyvinyl alcohol treatment on this fabric gives the good results expected for the garment applications.

Keywords: Polyethylene Terephthalate (Polyester), Polyvinyl Alcohol, Scanning Electron Microscope, Fourier-Transform Infrared Spectroscopy, X-Ray Diffraction

\section{INTRODUTION}

Polyethylene terephthalate (PET), commonly called as Polyester is the term used to denote the long-chain polymers chemically composed of at least $85 \%$ by weight of an ester and a dihydric alcohol and a terephthalic acid. The reaction of alcohol with carboxylic acid results with the formation of esters. Polyester is a general term in which the work poly- meaning many, and ester, a basic organic chemical compound AATCC test method 197-2011, AATCC test method 20A-2002, AATCC test method 79-2010. Polyester was one of the important and prominent man-made fiber discoveries of the forties and being manufactured for industrial scale since 1947. Polyester fibrous materials are the first choice for the production of apparel and are used in trousers, skirts, shirts, suits, jackets, blouses, home furnishings, hats, bed sheets, blankets, upholstered furniture and computer mouse mats AATCC test method 20A-2002, Bal, S, \& Behera, RC 2006, Barker AF 2004. Moreover, industrial polyester fibers, yarns and ropes are used in different reinforcement materials, fabrics for conveyor belts, safety belts, coated fabrics and plastic reinforcements with high-energy absorption aspects. 
Polyester fiber is also in the usage as cushioning and insulating material in pillows, comforters and upholstery padding 4,6,7. Polyester fabrics can provide specific advantages over natural fabrics, such as improved wrinkle resistance, durability and high color retention). As a result, polyester fibers are sometimes spun together with natural fibers to produce a cloth with blended properties Campbell, IM 2000, Dave, J, Kumar, R, \& Srivastava, HC 1987, Faterpekar, SA, \& Potnis, SP 1981

One of the earliest and most widely accepted method is treatment of PET fabric with sodium hydroxide. It is least expensive method of surface treatment. After alkali treatment the fabric becomes soft and silky to touch, with reduced static charge and soiling behavior Finch, CA, Polyvinyl alcohol 1973, Gohil, JM, Bhattacharya, A. and Ray, P. 2006, Hearle, JWS 1972. The improved performance of alkali treated PET fabric can be attributed to increase in surface roughness of the fiber and polar groups generated as a result of hydrolysis of ester linkage Gohil, JM, Bhattacharya, A. and Ray, P. 2006, J. Jeyakodi Moses, and Gnanapriya 2016, J. Shao, J. Zheng, J. Liu, C.M. Carr 2005. Poly(vinyl alcohol) is a water soluble and biodegradable synthetic polymer. It is a dry solid, and is available in granule and powdered forms. Most of the properties of polyvinyl alcohol depend on the degree of polymerization and the degree of hydrolysis. Degree of hydrolysis refers to the ratio of hydrophilic alcohol group and hydrophobic acetate group. Higher the degree of polymerization, the higher will be the viscosity of solution and adhesive strength Kimizu, M, Shimb, Y, Abe, T, \& Hori, T 2005, Kish, MH, \& Nouri, M 1999, Kudlacek, L, Hepnan, M, \& Kasparova, Z 1986. Accordingly, in this work, an attempt is made to treat the polyester fabric with sodium hydroxide followed by polyvinyl alcohol in different concentrations and to select the optimum values. The output of the work gives convincing results suitable for the polyester fabric in the conventional garment and apparel end use applications.

\section{EXPERIMENTAL}

\subsection{MATERIALS}

The $100 \%$ plain woven polyester fabric (polyethylene terephthalate) with the specifications such as; yarn count (both warp and weft) - 85, GSM - 68, cover factor - 15.83, ends per inch - 92, picks per inch - 80. The chemicals such as; polyvinyl alcohol, $\left(\mathrm{C}_{2} \mathrm{H}_{4} \mathrm{O}\right)_{\mathrm{n}}$; degree of polymerization $1700-1900$, sodium hydroxide $(\mathrm{NaOH})$, hydrochloric acid $(\mathrm{HCl})$, acetic acid $\left(\mathrm{CH}_{3} \mathrm{COOH}\right)$, disperse dye (CI number : 64500 ) etc. used in this study are in analytical grade.

\subsection{METHODS}

\subsubsection{PRE-TREATMENT OF POLYESTER FABRIC}

The $100 \%$ raw polyester fabric was desized by immersing in $10 \mathrm{~g} / \mathrm{l}$ (gram per litre) hydrochloric acid solution at ambient temperature for one hour with the material to liquor ratio (MLR) 1:20; in order to remove the added size impurities so as to facilitate the smooth subsequent processes. After desizing the polyester fabric was thoroughly washed and dried Kulshreshtha, AK, Khan, AH, \& Madan, GL 1978, Ledford, WT, \& Wasson, JR 1989. 


\subsubsection{TREATMENT OF POLYESTER FABRIC WITH SODIUM HYDROXIDE}

The desized polyester fabric was treated with sodium hydroxide of concentration $5 \%, 10 \%$ and $15 \%(\mathrm{w} / \mathrm{v}$ ) for 30 minutes at $50 \mathrm{oC}$ for imparting swelling and partial hydrolysis in the polyester polymer arrangements Li, Y, Neoh, K.G, \& Kang, ET 2004, Ludewig, H 1964.

\subsubsection{TREATMENT OF POLYESTER FABRIC WITH POLYVINYL ALCOHOL}

The sodium hydroxide treated polyester fabric was subjected with polyvinyl alcohol in alkaline medium (maintained by $1 \mathrm{~N} \mathrm{NaOH}, \mathrm{pH} 8.5$ ) with concentration of $3 \%, 5 \%$, and $10 \%(\mathrm{w} / \mathrm{v})$ for 30 minutes at $80 \mathrm{oC}$. After this the polyester fabric was dried at $105 \mathrm{oC}$ for 30 minutes and cured at $140 \mathrm{oC}$ for $120 \mathrm{sec}$. Then the polyester fabric was thoroughly washed and dried Namboodri, CGG, \& Haith, MS 1968, Namboodri, CGG, \& Haith, MS 1968.

\subsubsection{DYEING OF POLYESTER FABRIC}

The polyester fabrics (desized, sodium hydroxide treated, polyvinyl alcohol treated) were dyed with disperse dye of $2 \%$ (owm) concentration for two hours at around $950 \mathrm{o}$ and the MLR maintained was 1:20; so as to confirm the effect of alkaline polyvinyl alcohol application. After dyeing the polyester fabric was soaped, washed and dried Nimchua, T, Eveleigh, DE, Sangwatanaroj, U, \& Punnapayak, H 2008, Ohe, T, Yoshimura, Y, \& Abe, I 2007, Ohguchi, M, Igeta, K, \& Yashumura, T 1980.

\subsubsection{MEASUREMENT OF PHYSICAL PROPERTIES OF THE POLYESTER FABRIC}

The physical properties such as tensile strength, elongation, drapeability, thermal resistance, and stiffness of the polyester fabric were measured by the standard established methods such as grab tensile test method, Elmendorf tear tester as per ASTM D1424 - 2009, Cusik Drapemeter, Rth = L/k, ((m2 으)/W), and Shirley stiffness tester respectively Pajgrt, O, \& Reichstadter, B 1979, Pellew, C 1998, Peters, RH.

\subsubsection{ABSORPTION OF THE POLYESTER FABRIC}

The absorption characteristics of the polyester fabric (desized, sodium hydroxide treated, polyvinyl alcohol treated and the subsequent dispersed dyed) such as, drop absorbency, water retention and wicking were determined as per the AATCC test methods Petukov, BV 1963, Prorokova, NP, Vavilova, SY, \& Prorokov, VN 2007, Prorokova, NP, Vavilova, SY, \& Prorokov, VN 2007, Rajendran, S, \& Mishra, SP 2007. 


\subsubsection{SEM STUDY OF THE POLYESTER FABRIC}

The polyester fabric (desized, sodium hydroxide treated, polyvinyl alcohol treated and the subsequent dispersed dyed) was subjected for scanning electron microscope study using $30 \mathrm{kV}$ scanning electron microscope, JEOL (Japan) Model JSM-6360 Ramachandran, T, \& Kesavaraja, N 2004, Roberts, RC 1969.

\subsubsection{FTIR ANALYSIS OF THE POLYESTER FABRIC}

FTIR analysis was performed on the polyester fabric (sodium hydroxide treated, polyvinyl alcohol treated and the subsequent dispersed dyed) for studying the different functional groups, by the Fourier Transform Infra Red (FTIR) spectrophotometer (Shimadzu, Japan) S.Y. Oh, D.L.Yoo, Y. Shin, H.C. Kim, H.Y. Kim, Y.S. Chung, W.H. Park, J.H. Youk 2005, Sanders, EM, \& Zeronian, SH 1982.

\subsubsection{XRD ANALYSIS OF THE POLYESTER FABRIC}

XRD analysis was performed on the polyester fabric (sodium hydroxide treated, polyvinyl alcohol treated and the subsequent dispersed dyed) to understand the unknown crystalline materials using Shimadzu XRD6000 technique Sanders, EM, \& Zeronian, SH 1982, Saville, B.P, 2004, Uchida, E, Uyama, Y, \& Ikada, Y 1989.

\section{RESULTS AND DISCUSSION}

\subsection{PHYSICAL PROPERTIES OF THE POLYESTER FABRIC}

The physical properties, such as tensile strength, elongation, stiffness, drape co efficient and thermal resistance of the polyester fabric (desized, sodium hydroxide treated, polyvinyl alcohol treated and the subsequent dispersed dyed) are given in the Table 1. From the table it is visible that as the polyester fabric is undergone subsequent treatments, the tensile strength decreases both in the warp and weft way respectively in a considerable manner. However, the elongation is increased subsequently. In the same way, stiffness and thermal resistances are reduced; and drape co efficiency is increased in a marginal manner. All these changes are due to the effect of the sodium hydroxide and the polyvinyl alcohol treatments. Even though the polyester fabric was treated with sodium hydroxide $(5 \%, 10 \%$ and $15 \%$ $(\mathrm{w} / \mathrm{v})$ ) and polyvinyl alcohol $(3 \%, 5 \%$ and $10 \%(\mathrm{w} / \mathrm{v}))$ in different concentrations; only the optimum value is fixed for the different studies. Accordingly, the sodium hydroxide concentration is fixed as $10 \%(\mathrm{w} / \mathrm{v})$ and polyvinyl alcohol concentration is fixed as $5 \%(\mathrm{w} / \mathrm{v})$ respectively. Below and above these optimum values the effect was noticed to be very less, and hence it is continued further with the above noted optimum values. Also for the confirmation of the effect of these applications, finally the polyester fabric was dyed with disperse dye. 


\begin{tabular}{|c|c|c|c|c|c|c|c|c|c|}
\hline \multirow[t]{2}{*}{$\begin{array}{l}\text { S. } \\
\text { N } \\
\text { o. }\end{array}$} & \multirow[t]{2}{*}{$\begin{array}{l}\text { Treatme } \\
\text { nts on } \\
\text { polyeste } \\
\text { r fabric }\end{array}$} & \multicolumn{2}{|l|}{$\begin{array}{c}\text { Tensile } \\
\text { Strengt } \\
\text { h (N) }\end{array}$} & \multicolumn{2}{|l|}{$\begin{array}{l}\text { Elongat } \\
\text { ion (\%) }\end{array}$} & \multicolumn{2}{|l|}{$\begin{array}{l}\text { Stiffness } \\
\text { [Bending } \\
\text { length } \\
\text { cm] }\end{array}$} & \multirow[t]{2}{*}{$\begin{array}{c}\text { Drap } \\
\text { e co- } \\
\text { effici } \\
\text { ent } \\
(\%)\end{array}$} & \multirow[t]{2}{*}{$\begin{array}{l}\text { Thermal } \\
\text { resistance } \\
\left(\mathrm{m}^{2} \cdot \mathrm{mk} / \mathrm{w}\right. \\
\text { ) }\end{array}$} \\
\hline & & Warp & Weft & Warp & Weft & Warp & Weft & & \\
\hline 1 & Desized & 385.6 & 364.2 & 8.8 & 8.3 & 0.81 & 0.78 & 93.65 & 94.25 \\
\hline 2 & $\begin{array}{l}\text { Sodium } \\
\text { hydroxid } \\
\text { e treated }\end{array}$ & 379.3 & 358.7 & 9.2 & 8.7 & 0.8 & 0.77 & 94.26 & 93.82 \\
\hline 3 & $\begin{array}{c}\text { Polyvinyl } \\
\text { alcohol } \\
\text { treated }\end{array}$ & 381.5 & 360.6 & 9.3 & 8.8 & 0.8 & 0.77 & 94.24 & 93.65 \\
\hline 4 & Dyed & 381.8 & 361.2 & 9.3 & 8.8 & 0.8 & 0.77 & 94.25 & 93.67 \\
\hline
\end{tabular}

\subsection{ABSORPTION CHARACTERISTICS OF THE POLYESTER FABRIC}

The absorption characteristics like drop absorbency, water retention and wicking of the polyester fabric (desized, sodium hydroxide treated, polyvinyl alcohol treated and the subsequent dispersed dyed) are given in the Table 2. It is observed from the Table 2 that as the polyester fabric is undergone subsequent treatments (desizing, sodium hydroxide treatment, polyvinyl alcohol treatment), the absorption characteristics (drop absorbency, water retention and wicking) are increased in overall manner. In drop absorbency, the desized polyester fabric after treatment with sodium hydroxide $(10 \% \mathrm{w} / \mathrm{v})$ and subsequently with polyvinyl alcohol $(5 \% \mathrm{w} / \mathrm{v})$ the water drops are absorbed in less time. Correspondingly, the water retention on these polyester fabrics is considerably more in a respective manner. In the similar way, the wicking tendency is also increased with respect to this trend. All these increased effects are due to the influences of sodium hydroxide and polyvinyl alcohol in the polyester fabric. The sodium hydroxide at this specific concentration $(10 \% \mathrm{w} / \mathrm{v})$ induces the swelling aspects in the polymer chain and subsequently the application of polyvinyl alcohol $(5 \% \mathrm{w} / \mathrm{v})$ gives the reaction over the partially hydrolyzed polyester polymer and increased the reactivity and hence the hydrophilicity.

\begin{tabular}{|c|c|c|c|c|}
\hline \multirow[t]{2}{*}{ S. No. } & \multirow{2}{*}{$\begin{array}{c}\text { Treatments } \\
\text { on polyester } \\
\text { fabric }\end{array}$} & \multicolumn{3}{|c|}{ Absorption characteristics } \\
\hline & & $\begin{array}{c}\text { Drop absorbency } \\
\text { (sec) }\end{array}$ & $\begin{array}{c}\text { Water } \\
\text { retention } \\
(\%)\end{array}$ & $\begin{array}{c}\text { Wicking } \\
\text { (cm) [for } \\
45 \\
\text { minutes] }\end{array}$ \\
\hline 1 & Desized & 320 & 120 & 3.2 \\
\hline
\end{tabular}




\begin{tabular}{|c|c|c|c|c|}
\hline 2 & $\begin{array}{l}\text { Sodium } \\
\text { hydroxide } \\
\text { treated }\end{array}$ & 190 & 180 & 8.6 \\
\hline 3 & $\begin{array}{c}\text { Polyvinyl } \\
\text { alcohol treated }\end{array}$ & 165 & 190 & 10.7 \\
\hline 4 & Dyed & 167 & 189 & 10.7 \\
\hline
\end{tabular}

\subsection{SEM STUDY OF THE POLYESTER FABRIC}

The polyester fabrics subjected with different treatments (desized, sodium hydroxide treated, polyvinyl alcohol treated and the subsequent dispersed dyed) were undergone for SEM studies and the images of the them are shown in Figure 1. It is seen from these figure that there is a subsequent differences in the images of the SEM micrographs of the polyester fabrics (desized, sodium hydroxide treated, polyvinyl alcohol treated and the subsequent dispersed dyed). The improved effect subsequently is due to the effect of sodium hydroxide treatment and the periodical polyvinyl alcohol treatment and dyeing. A focused beam of high-energy electrons is used in scanning electron microscope to generate the variety of signals at the surface of solid textile samples. The electron-sample interactions provide signals that reveal the information about the samples including the texture (external morphology), crystalline structure and orientation of materials of the sample. The scanning electron microscope also provides the capability of performing analyses of selected point locations on the sample Roberts, RC 1969, Usenko, V 1979.
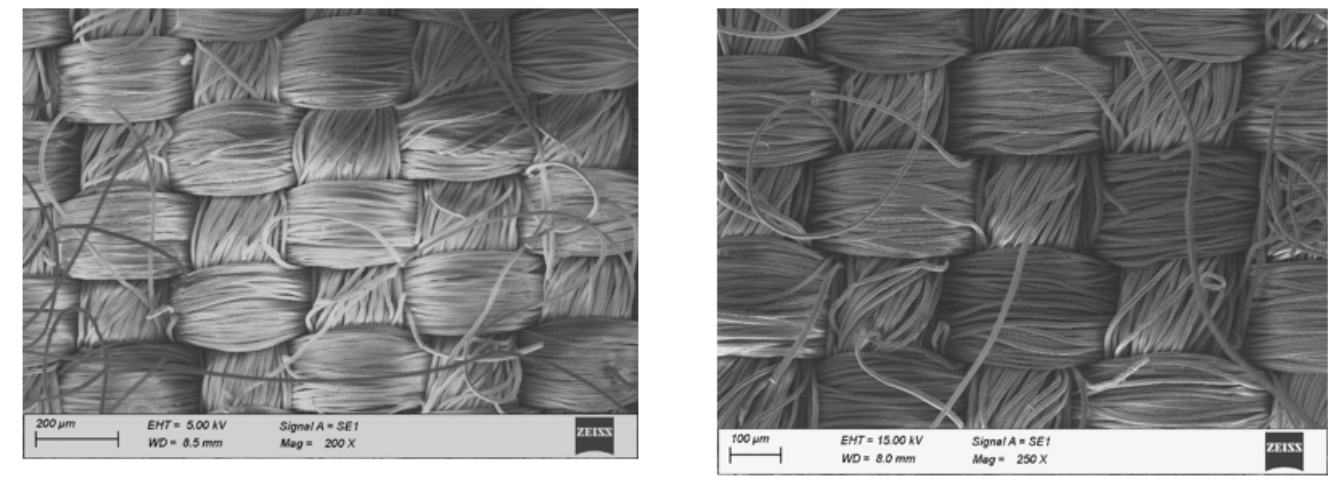

a) Desized polyester fabric
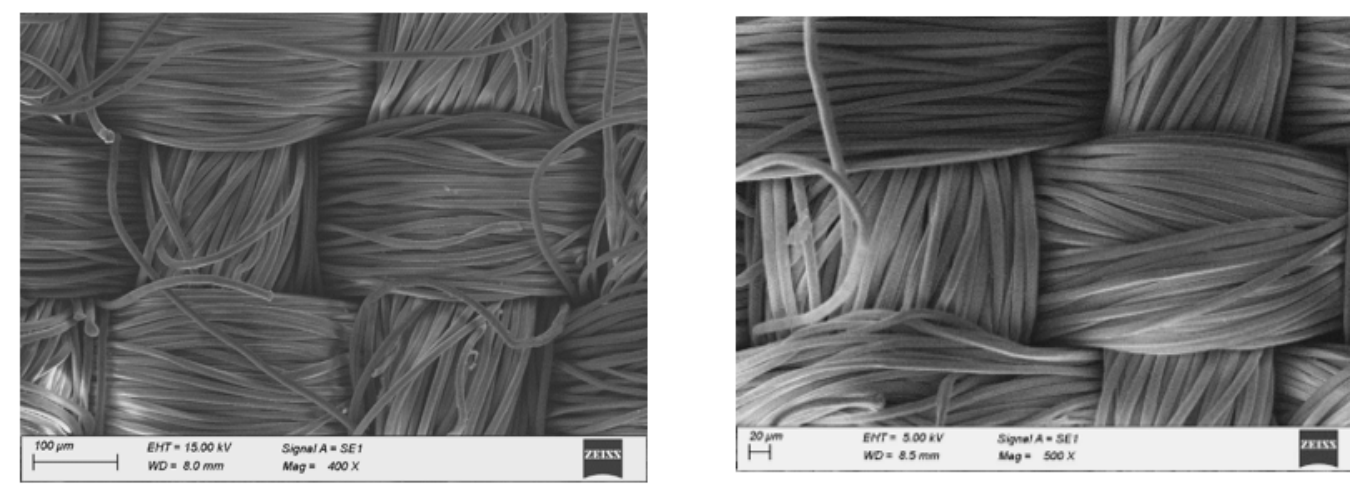

b) Sodium hydroxide treated polyester fabric 

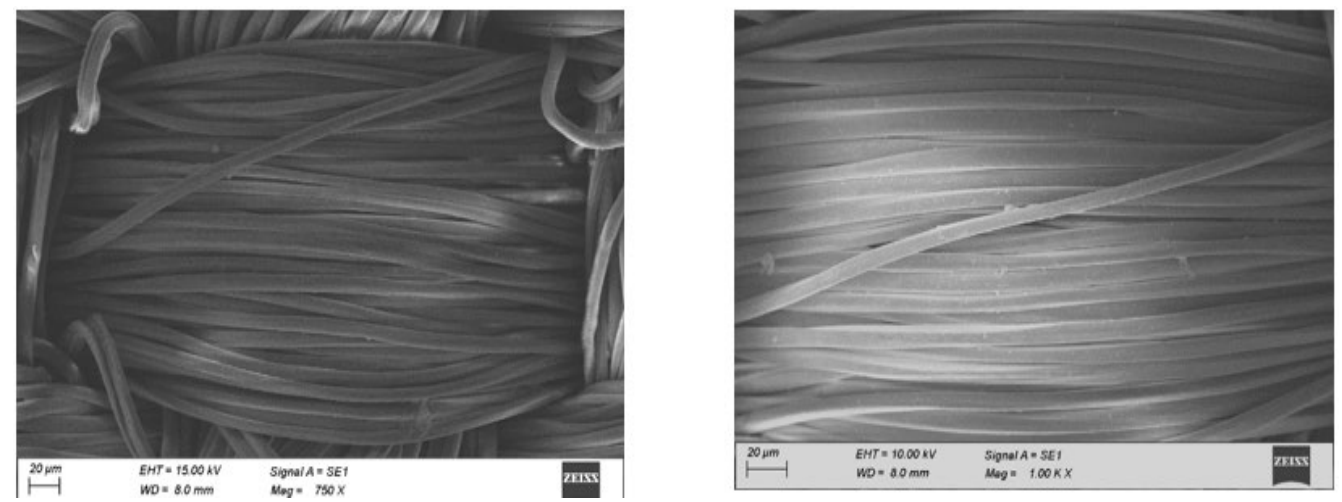

c) Sodium hydroxide and polyvinyl alcohol treated polyester fabric
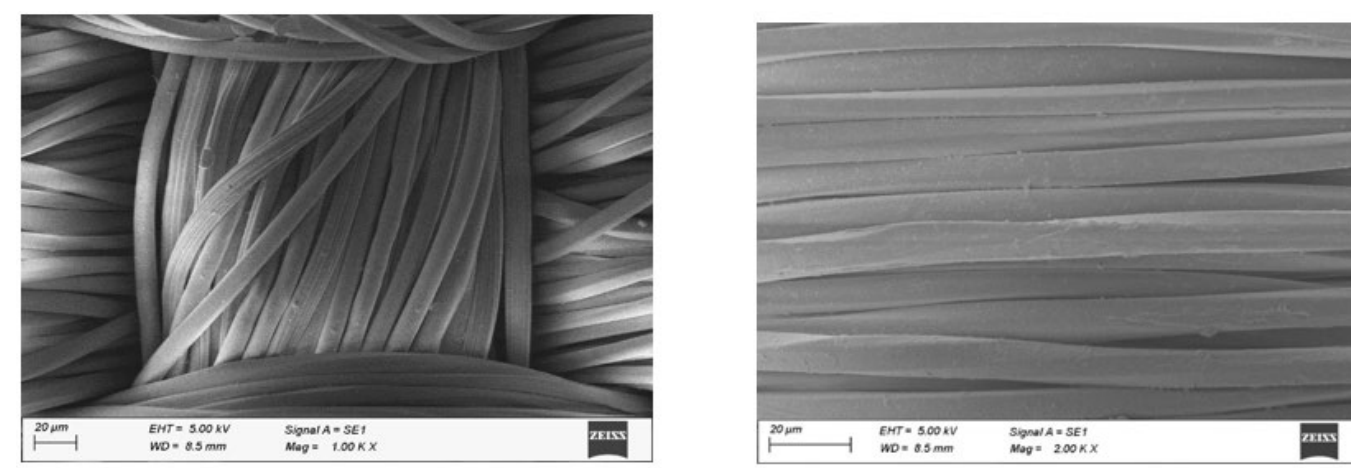

d) Sodium hydroxide, polyvinyl alcohol treated and dyed polyester fabric

Figure 1 SEM Micrographs of the Polyester Fabrics (a-desized, b-sodium hydroxide treated, cpolyvinyl alcohol treated and d-the subsequent dispersed dyed)

\subsection{FTIR ANALYSIS OF THE POLYESTER FABRIC}

The polyester fabrics treated with different treatments (desized, sodium hydroxide treated, polyvinyl alcohol treated and the subsequent dispersed dyed) were undergone for FTIR study and the graphs are shown in the Figure 2 FTIR graphs of the Polyester Fabrics (a-sodium hydroxide treated, b-polyvinyl alcohol treated and c-the subsequent dispersed dyed) and Figure 2a respectively. These graphs give the indication about the effect of sodium hydroxide and the subsequent polyvinyl alcohol on the polyester fabrics. From the Figures 2 and $2 \mathrm{a}$ it is revealed that as the polyester fabrics are treated with sodium hydroxide and the polyvinyl alcohol, the peak area of FTIR graph is differed which gives the indication for the effect of application on the polyester fabric. It can be observed that the broad peak in the spectra of polyvinyl alcohol treated polyester fabrics has influenced in peak intensity which indicates that the surface hydroxyl $(\mathrm{OH})$ groups in the polyester fabric and indicates the presence of polyvinyl alcohol over the polyester fabric surface. The IR bands shown are in the region of $1700-600 \mathrm{~cm}$ and correspond to $\mathrm{C}=\mathrm{O}, \mathrm{C}-\mathrm{O}$ and $\mathrm{C}-\mathrm{H}$ vibrations respectively37, 41, 42. The important other peaks are due to the $\mathrm{O}-\mathrm{H}$ stretching which is around 3600 to 3700 with reference to the standard data shown in the Table 3. 


\begin{tabular}{|c|c|c|}
\hline S. No. & Peak Range $\left(\mathrm{cm}^{-1}\right)$ & Functional Groups \\
\hline 1 & $3600-3700$ & Non bonded hydroxyl group-OH- \\
\hline 2 & $3300-3400$ & Alkyne -C-H-stretch \\
\hline 3 & $3200-3300$ & Hydroxyl group ( H-bonded -OH- stretch ) \\
\hline 4 & $3000-3200$ & Aromatic ring (-C-H-stretch) \\
\hline 5 & $2900-3000$ & Methylene -CH- stretch \\
\hline 6 & $2700-2800$ & Terminal aldehyde -CH- stretch \\
\hline 7 & $2600-2700$ & Hydrogen bonded -OH-group \\
\hline 8 & $2500-2600$ & Thiols (-S-H- stretch) \\
\hline 9 & $2400-2500$ & -CH- stretch of aromatic compounds \\
\hline 10 & $2300-2400$ & -OH-stretching of Carboxylic acid \\
\hline 11 & $2200-2300$ & Cyano compounds, disubstituted alkynes \\
\hline 12 & $2100-2200$ & C-triple bond-C-stretch \\
\hline 13 & $2000-2100$ & Cyanide ion and related ion \\
\hline 14 & $1800-2000$ & Transition metal carbonyl group \\
\hline 15 & $1700-1800$ & Carbonyl group \\
\hline 16 & $1600-1700$ & -C-double bond-C stretch \\
\hline 17 & $1500-1600$ & Aromatic ring stretch-NH-bend \\
\hline 18 & $1400-1500$ & Organic Sulphates \\
\hline 19 & $1300-1400$ & -OH- bend \\
\hline 20 & $1200-1300$ & Aromatic primary amine $-\mathrm{CN}$ - stretch \\
\hline 21 & $1100-1200$ & Secondary amine -CN- stretch \\
\hline 22 & $1000-1100$ & -C-C-stretch \\
\hline 23 & $900-1000$ & Cyclo hexane ring vibrations \\
\hline 24 & $800-900$ & Peroxides-C-0-O-stretch \\
\hline 25 & $700-800$ & Skeletal -C-C- vibrations \\
\hline 26 & $600-700$ & Aliphatic Bromo compounds \\
\hline 27 & $500-600$ & -C-I- stretch \\
\hline
\end{tabular}




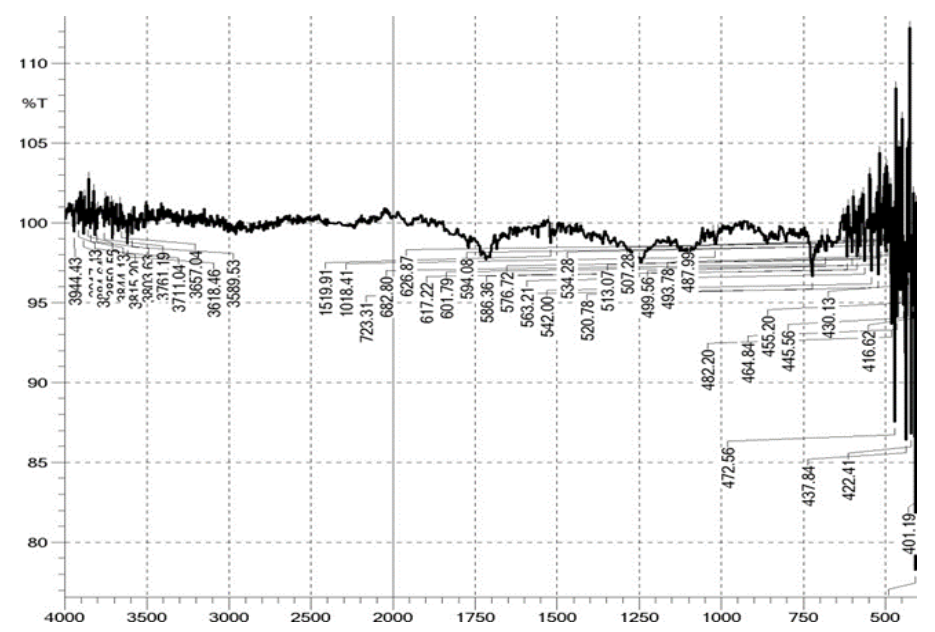

a) Sodium hydroxide treated polyester fabric

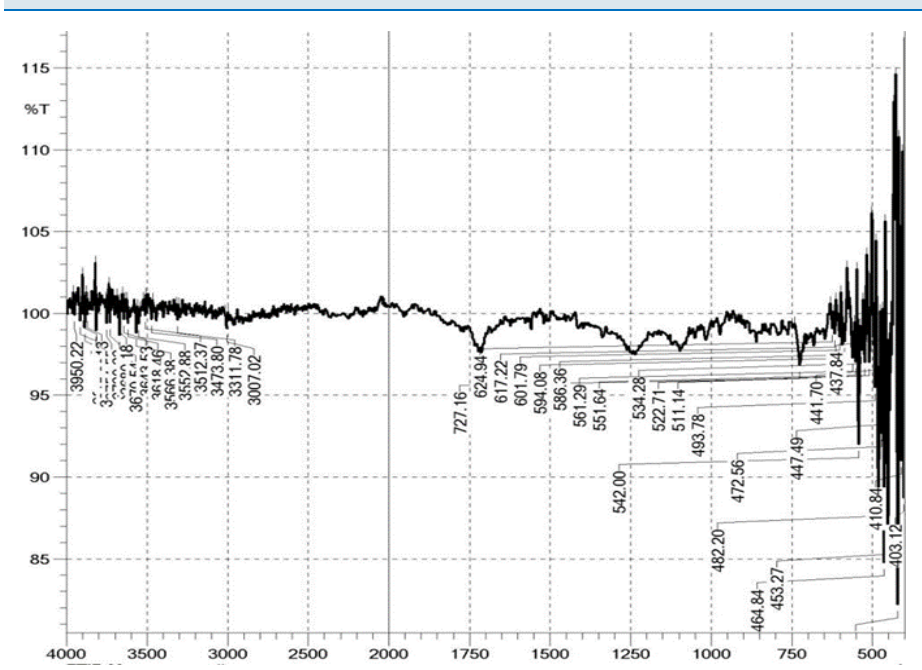

b) Sodium hydroxide and polyvinyl alcohol treated polyester fabric

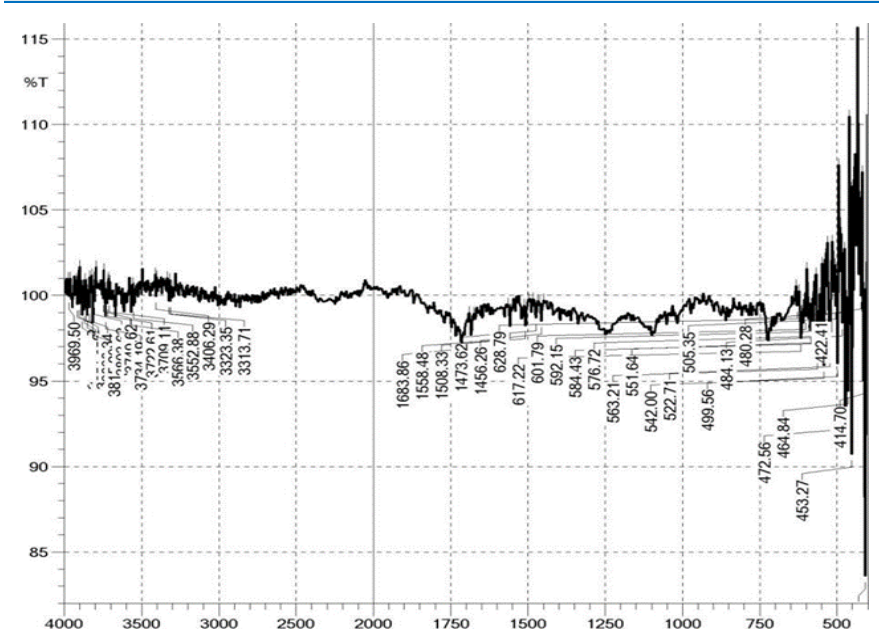

c) Sodium hydroxide, polyvinyl alcohol treated and dyed polyester fabric

Figure 2 FTIR graphs of the Polyester Fabrics (a-sodium hydroxide treated, b-polyvinyl alcohol treated and c-the subsequent dispersed dyed) 


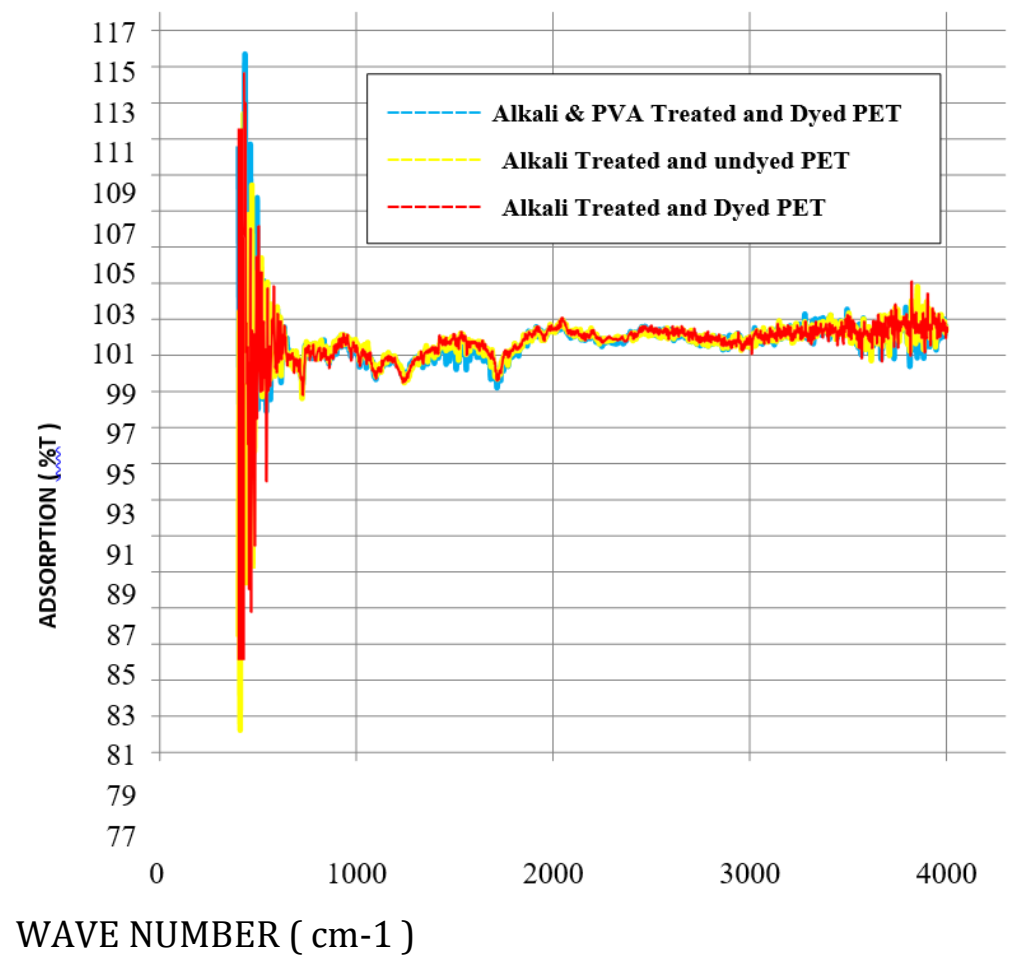

Figure 2a Combined FTIR graphs of the polyester fabric (a - sodium hydroxide polyvinyl alcohol treated and c - the subsequent dispersed dyed)

treated, $\mathrm{b}$ -

\section{XRD ANALYSIS OF THE POLYESTER FABRIC}

The polyester fabrics treated with sodium hydroxide, sodium hydroxide followed by polyvinyl alcohol, and their subsequent disperse dyeing respectively are subjected for XRD study and the graphs are shown in the Figure 3 XRD spectrograms of the Polyester Fabrics (a-sodium hydroxide treated, b-polyvinyl alcohol treated and c-the subsequent dispersed dyed). These spectrograms give the indication about the effect of sodium hydroxide treatment and the polyvinyl alcohol treatment on the polyester fabrics. From the Figure $3(\mathrm{a}, \mathrm{b} \& \mathrm{c})$ it is revealed that as the polyester fabrics are treated with sodium hydroxide, polyvinyl alcohol and their subsequent disperse dyeing, the bandwidth of the XRD graph is differed which gives the indication for the effect of application in these conditions on the polyester fabric. $\mathrm{X}$-ray diffraction is a common materials characterization technique that allows for identification of crystal orientations and inter-atomic spacing. X-rays are used for this because the wavelength is on the same length scale as inter-atomic spacing and lattice parameter values. The presence of characteristic peaks corresponding to the polyester crystalline in the XRD pattern of the respective treated fabrics indicates that the treatment of sodium hydroxide and polyvinyl alcohol on the polyester fabric surface does not affect the inherent crystalline structure of the polymer; rather it enhances the increase of the hydrophilic functional groups Uchida, E, Uyama, Y, \& Ikada, Y 1989, Zhang, C, Yang, F, Wang, W, \& Chen, B 2008, Zhifeng, Z, \& Kun, Q 2007. 


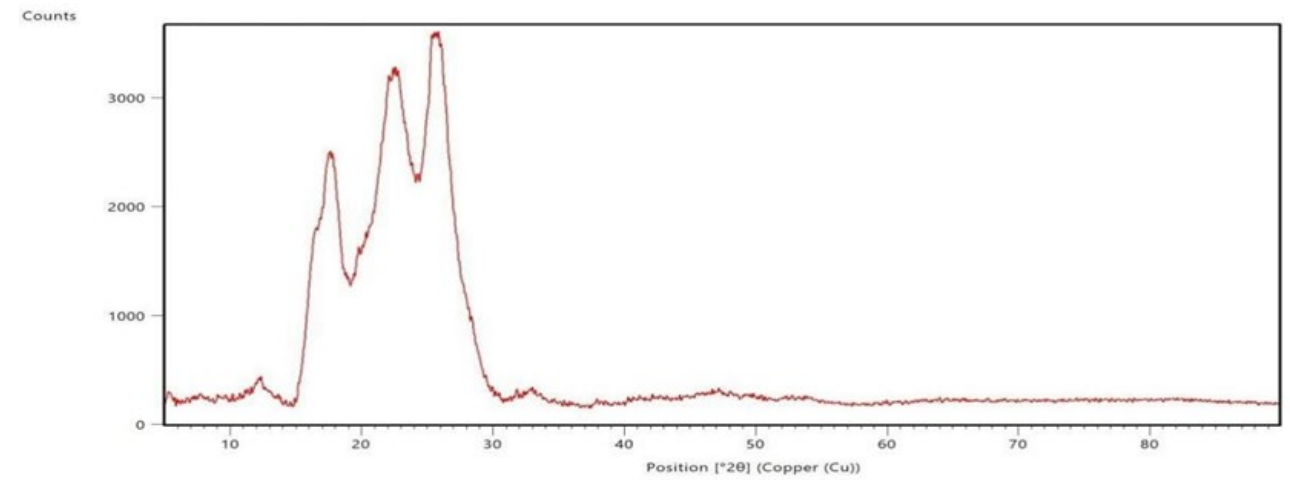

a) Sodium hydroxide treated polyester fabric

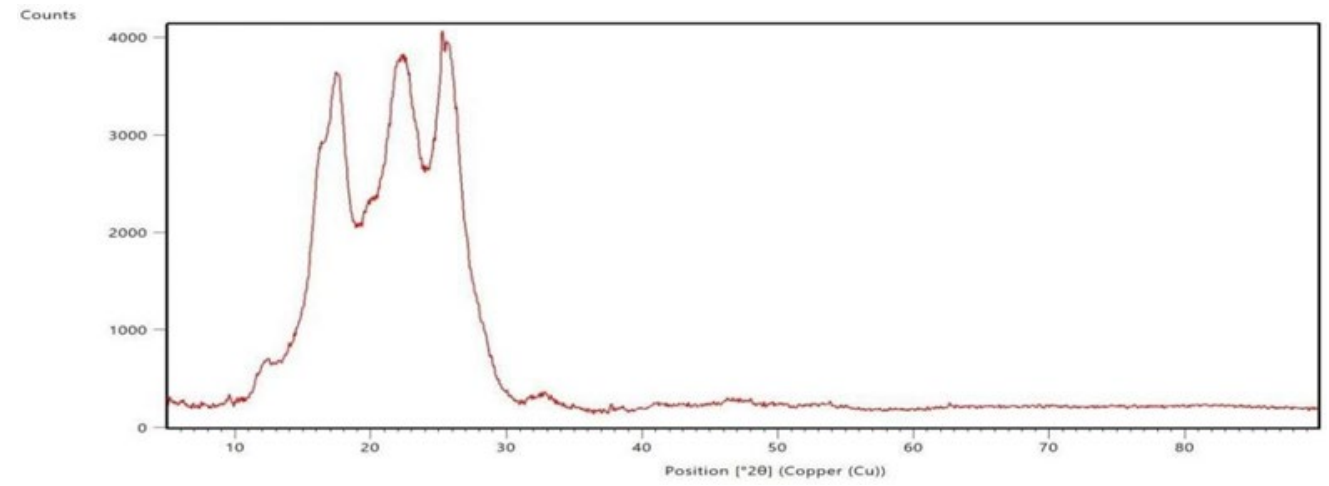

b) Sodium hydroxide and polyvinyl alcohol treated polyester fabric

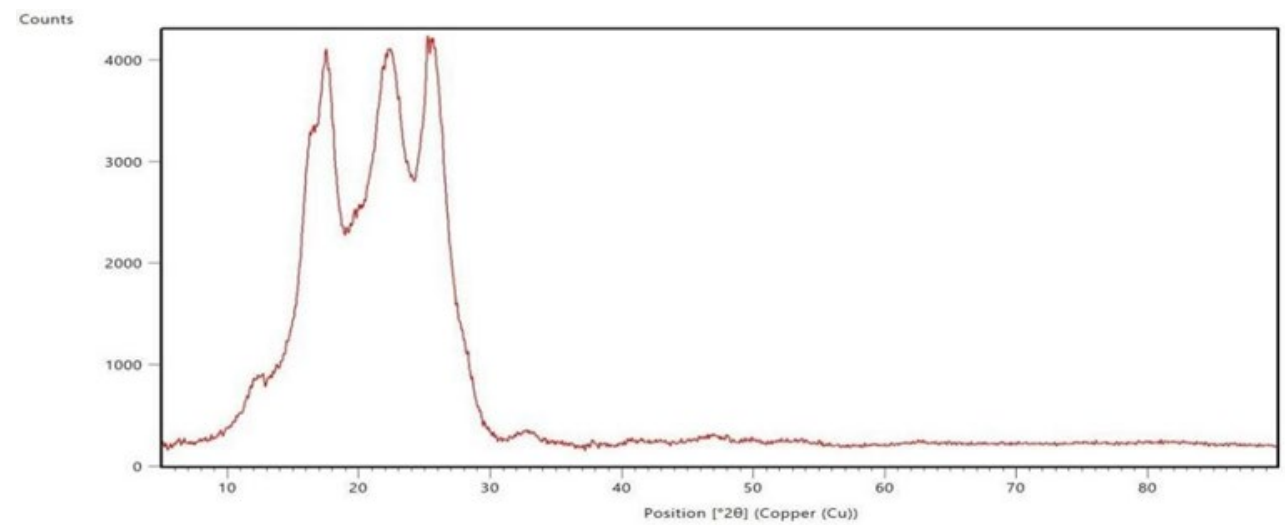

c) Sodium hydroxide, polyvinyl alcohol treated and dyed polyester fabric

Figure 3 XRD spectrograms of the Polyester Fabrics (a-sodium hydroxide treated, b-polyvinyl alcohol treated and c-the subsequent dispersed dyed) 


\section{CONCLUSION}

From this research work, it is observed that the physical properties of the sodium hydroxide treated and polyvinyl alcohol treated polyester fabric are not affected considerably, rather maintained in the expected limit. The absorption characteristics of the sodium hydroxide and polyvinyl alcohol treated polyester fabric are improved considerably. The SEM micrographs reveal the presence of the impact of the polyvinyl alcohol in the polyester fabric. The FTIR graphs indicate the influence of the application of sodium hydroxide and the subsequent polyvinyl alcohol treatment as well as disperse dyeing in the polyester fabric to secure the value of hydrophilic characters. The XRD spectrogram pronounce the good effect of treatments of sodium hydroxide, polyvinyl alcohol and the subsequent disperse dyeing in the polyester fabric

\section{ACKNOWLEDGEMENT}

The authors sincerely wish to express the gratitude to the Management and the Principal, PSG College of Technology, Coimbatore for given the permission to utilize the required infrastructures. The authors also wish to acknowledge the thanks to the Head, Department of Applied Science, PSG College of Technology for the kind help rendered in the completion of this work.

\section{REFERENCES}

AATCC test method 197-2011, "Vertical wicking of textiles", Technical Manual of the AATCC, Research Triangle Park, U.S.A, 2011.

AATCC test method 20A-2002, "Fiber Analysis: Quantitative", Technical manual of the AATCC, Research Triangle Park, U.S.A., 2002.

AATCC test method 79-2010, "Absorbecy of textiles", Technical manual of the AATCC, Research Triangle Park, U.S.A., 2010.

Bal, S, \& Behera, RC 2006 "Structural investigation of chemical treated polyester fibers using SAXS and other techniques", J. Miner. Mater. Charact. Eng., Vol. 5, No. 2, pp. 179-198. Retrieved from https://doi.org/10.4236/jmmce.2006.52013

Barker AF 2004, 'Hand book of Textiles', Abhishek Publications, Chandigarh.

Brandrup, J, \& Immergut, EH 1989, 'Polymer Handbook', John Wiley, New York,

Campbell, IM 2000, "Introduction to synthetic polymers", Oxford University Press, New York.

Dave, J, Kumar, R, \& Srivastava, HC 1987, "Studies on modification of polyester fabrics I: Alkaline hydrolysis", J. Appl. Polym. Sci., Vol. 33, pp. 455-477. Retrieved from https://doi.org/10.1002/app.1987.070330215

Faterpekar, SA, \& Potnis, SP 1981, "Dyeing of Grafted Polyester Fiber- Part I Effect of Poly (vinyl acetate) Graft on Dyeing Characteristics", Text. Res. J., Vol. 51, No. 7, pp. 448-453 Retrieved from https://doi.org/10.1177/004051758105100703 
Finch, CA, Polyvinyl alcohol1973: Properties and Applications, John Wiley \& Sons, New York.

Gohil, JM, Bhattacharya, A. and Ray, P. 2006 " Studies on the Cross-linking of Poly (Vinyl Alcohol)", J. Polym. Res., Vol. 13, pp. 161-169. Retrieved from https://doi.org/10.1007/s10965-005-9023-9

Hearle, JWS 1972, Use of the Scanning Electron Microscope, Pergamon Press, Oxford.

J. Jeyakodi Moses, and Gnanapriya 2016, A study on modal fabric using formic acid treatment for K/S, SEM and fourier transform infrared spectroscopy. Oriental Journal of Chemistry 32 (2) : 1099. Retrieved from https://doi.org/10.13005/ojc/320235

J. Shao, J. Zheng, J. Liu, C.M. Carr 2005, Fourier transform Raman and Fourier transform infrared spectroscopy studies of silk fibroin. J. of Applied Polymer Science., 96, 1999-2004. Retrieved from https://doi.org/10.1002/app.21346

Kimizu, M, Shimb, Y, Abe, T, \& Hori, T 2005, "Alkali hydrolysis of polyester fabric under ultra-high pressure", Fiber, Vol. 61, No. 4, pp. 109-114. Retrieved from https://doi.org/10.2115/fiber.61.109

Kish, MH, \& Nouri, M 1999, "Effects of sodium hydroxide and calcium hydroxide on polyester fabrics", J. Appl. Polym. Sci., Vol. 72, pp. 631-637. Retrieved from

https://doi.org/10.1002/(SICI)1097-4628(19990502)72:5<631::AIDAPP3>3.0.CO;2-A

Kudlacek, L, Hepnan, M, \& Kasparova, Z 1986, Morphology of Polymers, Ed by Sedlacek, B., Walter De Gruyter and Co, New York,.

Kulshreshtha, AK, Khan, AH, \& Madan, GL 1978, "X-ray diffraction study of solventinduced crystallization in polyester filaments," Polymer, vol. 19, no. 7, pp. 819-823 Retrieved from https://doi.org/10.1016/00323861(78)90011-3

Ledford, WT, \& Wasson, JR 1989, "Polyester fibers, yarns, and fabrics with enhanced hydrophilicity and method of producing the same with borohydride anions and lithium cations", US Patent 4808188, Gastonia, N.C.

Li, Y, Neoh, K.G, \& Kang, ET 2004, "Poly (vinyl alcohol) hydrogel fixation on poly (ethylene terephthalate) surface for biomedical application", Polymer, Vol.45, pp. 8779-8789. Retrieved from https://doi.org/10.1016/j.polymer.2004.10.077

Ludewig, H 1964, "Polyester Fibers-Chemistry and Technology", John Wiley \& Sons, London.

Namboodri, CGG, \& Haith, MS 1968, "Steric effects in the basic hydrolysis of poly (ethylene terephthalate)", J. Appl. Polym. Sci., Vol. 12, No. 9, pp. 1999-2005. Retrieved from https://doi.org/10.1002/app.1968.070120901

Namboodri, CGG, \& Haith, MS 1968, "Steric effects in the basic hydrolysis of poly (ethylene terephthalate)", J. Appl. Polym. Sci., Vol. 12, No. 9, pp. 1999-2005. Retrieved from https://doi.org/10.1002/app.1968.070120901 
Nimchua, T, Eveleigh, DE, Sangwatanaroj, U, \& Punnapayak, H 2008, "Screening of tropical fungi producing polyethylene terephthalate- hydrolyzing enzyme for fabric modification", J.Ind. Microbiol. Biotechnol., Vol. 35, pp. 843-850. Retrieved from https://doi.org/10.1007/s10295-008-0356-3

Ohe, T, Yoshimura, Y, \& Abe, I 2007, "Chemical introduction of sugars onto PET fabrics using diamine and cyanuric chloride", Text. Res. J., Vol. 77, No. 3, pp. 131-137. Retrieved from https://doi.org/10.1177/0040517507076325

Ohguchi, M, Igeta, K, \& Yashumura, T 1980, "Grafting of vinyl monomers onto synthetic Fibres, Part 2 :one step grafting onto poly (ethylene terephthalate) using benzoyl peroxide", Sen-i Gakkaishi, Vol. 36, pp. T435-T442. Retrieved from https://doi.org/10.2115/fiber.36.10_T435

Pajgrt, O, \& Reichstadter, B 1979, "Processing of Polyester Fibers", Elsevier Scientific Publishing Company, New York.

Pellew, C 1998, 'Dyes and Dyeing', Abhishek Publications, Chandigarh, India.

Peters, RH, 'The Physical Chemistry of Dyeing", Elsevier Scientific Publications Company.

Petukov, BV 1963, "The Technology of Polyester Fibers", Pergamon Press, Oxford.

Prorokova, NP, Vavilova, SY, \& Prorokov, VN 2007, "Effect of ammonium salts on poly (ethylene terephthalate) materials", Fiber. Chem., Vol. 39, No. 1, pp. 2025. Retrieved from https://doi.org/10.1007/s10692-007-0005-z

Prorokova, NP, Vavilova, SY, \& Prorokov, VN 2007, "Effect of quarternary ammonium compound preparations on poly (ethylene terephthalate) fiber", Fiber. Chem., Vol. 39, No. 6, pp. 445-449. https://doi.org/10.1007/s10692007-0097-5

Rajendran, S, \& Mishra, SP 2007, "Chemical, structural and thermal changes in PET caused by solvent induced polymer crystallisation," Polymers and Polymer Composites, vol. 15, no. 2, pp. 103-110. Retrieved from https://doi.org/10.1177/096739110701500203

Ramachandran, T, \& Kesavaraja, N 2004, "A study on influencing factors for wetting and wicking behaviour", Institute of Engineers (India)-Textile Engineering, Vol. 84, pp. 37-41.

Roberts, RC 1969, "Poly (ethylene terephthalate) I-Heat of fusion", Polymer, Vol. 10, pp. 113-116. Retrieved from https://doi.org/10.1016/00323861(69)90014-7

S.Y. Oh, D.L.Yoo, Y. Shin, H.C. Kim, H.Y. Kim, Y.S. Chung, W.H. Park, J.H. Youk 2005, Crystalline structure analysis of cellulose treated with sodium hydroxide by means of X-ray diffraction and FTIR spectroscopy. Carbohydrate Research, 340, 2376-2391. Retrieved https://doi.org/10.1016/j.carres.2005.08.007

Sanders, EM, \& Zeronian, SH 1982, "An analysis of moisture related properties of hydrolysed polyester", J. Appl. Polym. Sci., Vol. 27, pp. 4477-4491. Retrieved from https://doi.org/10.1002/app.1982.070271135

Saville, B.P, 2004, "Physical testing of textiles", wood head Publishing Ltd and CRC Press, Cambridge, England., pp, 205-210. 
Uchida, E, Uyama, Y, \& Ikada, Y 1989, "Surface graft polymerization of acrylamide onto Poly (ethylene terephthalate) film by UV irradiation", J. Polym. Sci. Polym. Chem., Vol. 27, pp. 527-537. Retrieved from https://doi.org/10.1002/pola.1989.080270213

Usenko, V 1979, "Processing of Man Made Fibers", MIR Publishing, Moscow.

Xi, X, Yuhai, G, \& Wen, X 2003, "Preparation method of polyethylene terephthalate / polyvinyl alcohol hydrogen bond complex fabric", China Patent 01108689, Sichuan Univ.

Zhang, C, Yang, F, Wang, W, \& Chen, B 2008, "Preparation and characterization of hydrophilic modification of polypropylene non-woven fabric by dip-coating PVA (polyvinyl alcohol)", Sep. Purif. Technol., Vol. 61, No. 3, pp. 276-286. Retrieved from https://doi.org/10.1016/j.seppur.2007.10.019

Zhifeng, Z, \& Kun, Q 2007, "Effects of the molecular structure of poly (vinyl alcohol) on the adhesion to fiber substrates", Fibers. Text. East. Eur., Vol. 15, No. 1, pp. 82-85. 